Journal Club

Editor's Note: These short reviews of recent JNeurosci articles, written exclusively by students or postdoctoral fellows, summarize the important findings of the paper and provide additional insight and commentary. If the authors of the highlighted article have written a response to the Journal Club, the response can be found by viewing the Journal Club at www.jneurosci.org. For more information on the format, review process, and purpose of Journal Club articles, please see https://www.jneurosci.org/content/ jneurosci-journal-club.

\title{
Cardiorespiratory Dysfunction Induced by Brainstem Spreading Depolarization: A Potential Mechanism for SUDEP
}

\author{
DPedro Lourenco Katayama \\ Department of Physiology and Pathology, School of Dentistry, São Paulo State University, CEP 01049-010 Araraquara, São Paulo, Brazil \\ Review of Jansen et al.
}

Sudden unexpected death in epilepsy (SUDEP) is the main cause of death in people with refractory epilepsy (Massey et al., 2014; Buchanan, 2019), but the mechanisms responsible for SUDEP are still unclear. Evidence from animal and human studies suggests that SUDEP is related to an impairment in the central control of respiration, cardiac function, and arousal (Ryvlin et al., 2013; Massey et al., 2014; Buchanan, 2019). Given that all of these functions are essentially controlled by the brainstem, it is reasonable to postulate that the brainstem is involved in the pathophysiology of SUDEP. Indeed, some data indicate that cardiorespiratory arrest observed in experimental models of SUDEP is related to brainstem dysfunction (Aiba and Noebels, 2015). Nonetheless, its underlying mechanisms need further investigation.

A recent study published in The Journal of Neuroscience by Jansen et al. (2019) provides new insights into the potential mechanisms underlying SUDEP. The authors used a transgenic mouse model

\footnotetext{
Received Dec. 26, 2019; revised Feb. 9, 2020; accepted Feb. 17, 2020.

This work was supported by the Sao Paulo Research Foundation (FAPESP; Grant \#2019/11196-0).

The author declares no competing financial interests.

Correspondence should be addressed to Pedro Lourenco Katayama at katayamapl@gmail.com.

https://doi.org/10.1523/JNEUROSCI.3053-19.2020

Copyright $\odot 2020$ the authors
}

(Cacna1 $a^{\mathrm{S} 218 \mathrm{~L}}$ mice) carrying a homozygous S218L missense mutation that leads to gain of function of voltage-gated $\mathrm{CaV} 2.1 \mathrm{Ca}^{2+}$ channels and increased risk for spontaneous fatal seizures, and which has been proposed as a SUDEP model (Loonen et al., 2019). The main finding of Jansen et al. (2019) was that that cardiorespiratory dysfunction related to spontaneous brainstem seizures in Cacna $1 a^{\mathrm{S} 218 \mathrm{~L}}$ mice is caused by medullary spreading depolarization (SD). Cacnala ${ }^{\mathrm{S} 218 \mathrm{~L}}$ mice displayed lethal and nonlethal spontaneous seizures. All lethal seizures were accompanied by SD in the brainstem (oral pontine reticular nucleus and ventrolateral medulla), followed by suppression of neuronal activity in these areas, bradypnea, brainstem hypoxia, and bradycardia. In contrast, brainstem SD occurred in only a minority of nonlethal seizures, and, when it occurred, the brainstem DC potential and multiunit activity spontaneously recovered, the respiratory activity was rapidly restored, and heart rate did not significantly change. These findings, along with previous findings reported by this research group (Loonen et al., 2019), indicate that the Cacnala ${ }^{\mathrm{S} 218 \mathrm{~L}}$ mouse might be a useful model to study the mechanisms underlying SUDEP and that brainstem SD is a key feature for the cardiorespiratory dysfunction associated with lethal seizures in this model.
Jansen et al. (2019) also performed experiments to determine a causal relationship between brainstem SD and brainstem hypoxia. Because hypoxia can promote an SD-like event called anoxic depolarization (Ayata and Lauritzen, 2015), the authors wanted to ensure that $\mathrm{SD}$ is a cause and not a consequence of hypoxia during seizures. To accomplish this, the authors induced seizures by electrical stimulation of the inferior colliculus (IC) in Cacnala ${ }^{\mathrm{S} 218 \mathrm{~L}}$ and wild-type mice. This stimulation triggered ipsilateral brainstem SD in Cacnala ${ }^{\mathrm{S} 218 \mathrm{~L}}$ but not in wildtype mice. Brainstem SD in Cacnala $a^{\mathrm{S} 218 \mathrm{~L}}$ mice preceded apnea and brainstem hypoxia, demonstrating a causative role for brainstem SD in the initiation of seizurerelated apnea and subsequently hypoxia.

Another notable finding by Jansen et al. (2019) was that mechanical ventilation after seizures induced by electrical stimulation of the IC in Cacnala ${ }^{\mathrm{S} 218 \mathrm{~L}}$ mice was able to prevent death in seven of nine cases, suggesting that respiratory dysfunction plays an essential role in SUDEP. It is important to highlight that the ventilatory support was initiated at least $60 \mathrm{~s}$ (65-79s) after brainstem SD onset to ensure that mechanical ventilation was applied in cases of potentially lethal seizures. Even though the ventilatory support was initiated relatively late, it was sufficient to restore heart rate, ventrolateral medulla DC 
potential and multiunit activity, breathing, and ventrolateral medulla $\mathrm{PO}_{2}$, preventing death in the majority of cases. These data may have important implications for the clinical management of seizures, suggesting that interventions to restore ventilation in patients with periictal respiratory disturbances (hypoventilation/apnea) might be a valuable strategy to prevent death.

Finally, because the excitatory amino acid glutamate and its NMDA receptors are importantly implicated in the generation and propagation of SD (Ayata and Lauritzen, 2015), Jansen et al. (2019) tested whether NMDA receptor antagonism could prevent seizure-related deaths. The authors found that pharmacological interventions with NMDA receptor antagonists (MK-801 or memantine hydrochloride) administered intraperitoneally 30 min before IC stimulation prevented fatal outcomes in all cases and prevented brainstem SD in all except one case (one of eight animals treated with memantine hydrochloride). These results may encourage future clinical studies for the development of preventive strategies for SUDEP, especially on the potential benefits of NMDA antagonism in patients with a history of seizures associated with brainstem SD.

In the study by Jansen et al. (2019), analysis of the vigilance/sleep state of animals during fatal and nonfatal seizures could provide additional insights into the mechanisms involved in SUDEP. Most cases of SUDEP in humans occur at night during sleep (Lamberts et al., 2012; Ryvlin et al., 2013; Sveinsson et al., 2018). The mechanisms underlying this relationship are still unclear, but some studies have proposed that impaired $\mathrm{CO}_{2}$-induced arousal is involved (Nobili et al., 2011; Zhan et al., 2016; Buchanan, 2019). $\mathrm{CO}_{2}{ }^{-}$ induced arousal is an important protective reflex mechanism that depends on brainstem serotonergic neurons (Smith et al., 2018). Mice with genetic deletion of serotonergic neurons $\left(\operatorname{Lm} \times 1 b^{\mathrm{f} / \mathrm{f} / \mathrm{p}}\right.$ mice) do not arouse after stimulation of dorsal raphe nucleus (DRN) with acidosis; in addition, pharmacological or optogenetic acute inactivation of DRN serotonergic neurons abolish the $\mathrm{CO}_{2}$-induced arousal from sleep (Smith et al., 2018). In this regard, it has been suggested that abnormal brainstem serotonergic function could play an important role in SUDEP by impairing $\mathrm{CO}_{2}$-induced arousal during ictal and postictal periods (Zhan et al., 2016; Smith et al., 2018), likely aggravating apnea, hypoxia, and acidosis. Thus, it is plausible that the brainstem SD observed in Cacnala ${ }^{\text {S218L }}$ mice (Jansen et al., 2019) and other SUDEP mouse models (Aiba and Noebels, 2015) depresses the activity of DRN serotonergic neurons, impairing $\mathrm{CO}_{2}$-induced arousal from sleep, and, ultimately, contribute to fatal outcomes by worsening apnea, hypoxia, and acidosis during seizures.

The possible role of brainstem serotonergic neurons in SUDEP is not restricted to its function in $\mathrm{CO}_{2}$-induced arousal from sleep. Brainstem serotonergic neurons located in the medullary raphe play an important role in the control of breathing more generally (Richerson, 2004). These neurons are central chemoreceptors and, in conditions of increased $\mathrm{CO}_{2}$, provide a potent stimulatory drive to breath by sending excitatory projections to important respiratory areas such as the ventral respiratory column (VRC) and the retrotrapezoid nucleus (Richerson, 2004; Ptak et al., 2009). Therefore, the suppression of medullary raphe serotonergic inputs to respiratory nuclei would result in an inability to increase ventilation during situations of seizure-related apnea with elevated $\mathrm{CO}_{2}$ resulting in catastrophic outcomes. Of note, in addition to potentially contributing to SUDEP by controlling arousal and breathing mechanisms, serotonergic neurons can regulate seizure threshold (Buchanan et al., 2014) by affecting the excitability of seizure networks, perhaps including those in the brainstem.

Although Jansen et al. (2019) found that mechanical ventilation prevented death from seizures induced by IC stimulation indicating the essential role of respiratory dysfunction in SUDEP, the contribution of cardiovascular disturbances to SUDEP pathophysiology cannot be ruled out, especially since Cacnala ${ }^{\mathrm{S} 218 \mathrm{~L}}$ mice displayed both apnea and bradycardia during all fatal seizures. Under normal conditions, heart rate is maintained by tonic activity of preganglionic parasympathetic neurons, most of which reside in the nucleus ambiguus (NA; Dergacheva et al., 2010). At rest, a major glutamatergic projection arising from nucleus tractus solitarius (NTS) excites the cardiac preganglionic parasympathetic neurons, while GABAergic and glycinergic inputs from respiratory nuclei (VRC and pontine nuclei) inhibit the neurons during each inspiration, generating a physiological phenomenon called respiratory sinus arrhythmia (Neff et al., 2003; Dergacheva et al., 2010). Given that Jansen et al. (2019) found SD and sustained neuronal suppression in the ventral respiratory column during fatal seizures, it could be that the inhibitory inputs to NA were suppressed, allowing the excitatory input from NTS to strongly excite cardiac preganglionic parasympathetic neurons, resulting in profound bradycardia. Moreover, during fatal seizures, the excitatory input from NTS to NA might be further strengthened by the ongoing hypoxia, thus aggravating bradycardia and eventually causing cardiac arrest and death. Therefore, it could be possible that in the study by Jansen et al. (2019), treatment with NMDA receptor antagonists (MK801 or memantine hydrochloride) prevented seizure-related death by inhibiting this NTS-to-NA glutamatergic pathway. More studies are needed to test these hypotheses.

In conclusion, Jansen et al. (2019) revealed the crucial role of brainstem SD in the cardiorespiratory dysfunction during spontaneous and induced seizures in Cacnala $a^{\mathrm{S} 218 \mathrm{~L}}$ mice, providing new insights into the potential neural mechanisms underlying SUDEP. Future studies may help to identify the factors contributing to brainstem hyperexcitability; the role of specific respiratory, cardiovascular, and arousal mechanisms; and the precise brainstem nuclei and pathways involved in the pathophysiology of SUDEP in Cacnala $a^{\mathrm{S} 218 \mathrm{~L}}$ mice and other SUDEP models. Finally, it is noteworthy to highlight the translational potential of the findings reported by Jansen et al. (2019), which should direct future research and may help to develop preventive strategies for SUDEP.

\section{References}

Aiba I, Noebels JL (2015) Spreading depolarization in the brainstem mediates sudden cardiorespiratory arrest in mouse SUDEP models. Sci Transl Med 7:282ra46.

Ayata C, Lauritzen M (2015) Spreading depression, spreading depolarizations, and the cerebral vasculature. Physiol Rev 95:953-993.

Buchanan GF (2019) Impaired $\mathrm{CO}_{2}$-induced arousal in SIDS and SUDEP. Trends Neurosci 42:242-250

Buchanan GF, Murray NM, Hajek MA, Richerson GB (2014) Serotonin neurones have anticonvulsant effects and reduce seizure-induced mortality. J Physiol 592:4395-4410.

Dergacheva O, Griffioen KJ, Neff RA, Mendelowitz D (2010) Respiratory physiology and neurobiology respiratory modulation of premotor cardiac vagal neurons in the brainstem. Respir Physiol Neurobiol 174:102-110.

Jansen NA, Schenke M, Voskuyl RA, Thijs RD, van den Maagdenberg AMJM, Tolner EA (2019) Apnea associated with brainstem seizures in Cacnala ${ }^{\mathrm{S} 218 \mathrm{~L}}$ mice is caused by med- 
ullary spreading depolarization. J Neurosci 39:9633-9644.

Lamberts RJ, Thijs RD, Laffan A, Langan Y, Sander JW (2012) Sudden unexpected death in epilepsy: people with nocturnal seizures may be at highest risk. Epilepsia 53:253-257.

Loonen ICM, Jansen NA, Cain SM, Schenke M, Voskuyl RA, Yung AC, Bohnet B, Kozlowski P, Thijs RD, Ferrari MD, Snutch TP, van den Maagdenberg AMJM, Tolner EA (2019) Brainstem spreading depolarization and cortical dynamics during fatal seizures in Cacnala S218L mice. Brain 142:412-425.

Massey CA, Sowers LP, Dlouhy BJ, Richerson GB (2014) Mechanisms of sudden unexpected death in epilepsy: the pathway to prevention. Nat Rev Neurol 10:271-282.

Neff RA, Wang J, Baxi S, Evans C, Mendelowitz D (2003) Respiratory sinus arrhythmia: endogenous activation of nicotinic receptors mediates respiratory modulation of brainstem cardioinhibitory parasympathetic neurons. Circ Res 93:565-572.

Nobili L, Proserpio P, Rubboli G, Montano N, Didato G, Tassinari CA (2011) Sudden unexpected death in epilepsy (SUDEP) and sleep. Sleep Med Rev 15:237-246.

Ptak K, Yamanishi T, Aungst J, Milescu LS, Zhang R, Richerson GB, Smith JC (2009) Raphe neurons stimulate respiratory circuit activity by multiple mechanisms via endogenously released serotonin and substance p. J Neurosci 29:3720-3737.

Richerson GB (2004) Serotonergic neurons as carbon dioxide sensors that maintain $\mathrm{pH}$ homeostasis. Nat Rev Neurosci 5:449-461.

Ryvlin P, Nashef L, Lhatoo SD, Bateman LM, Bird J, Bleasel A, Boon P, Crespel A, Dworetzky BA, Høgenhaven H, Lerche H, Maillard L, Malter MP, Marchal C, Murthy JM, Nitsche M, Pataraia E, Rabben T, Rheims S, Sadzot B, et al. (2013) Incidence and mechanisms of cardio- respiratory arrests in epilepsy monitoring units (MORTEMUS): a retrospective study. Lancet Neurol 12:966-977.

Smith HR, Leibold NK, Rappoport DA, Ginapp CM, Purnell BS, Bode NM, Alberico SL, Kim YC, Audero E, Gross CT, Buchanan GF (2018) Dorsal raphe serotonin neurons mediate $\mathrm{CO}_{2}$-induced arousal from sleep. J Neurosci 38:1915-1925.

Sveinsson O, Andersson T, Carlsson S, Tomson T (2018) Circumstances of SUDEP: a nationwide population-based case series. Epilepsia 59:1074-1082.

Zhan Q, Buchanan GF, Motelow JE, Andrews J, Vitkovskiy P, Chen WC, Serout F, Gummadavelli A, Kundishora A, Furman M, Li W, Bo X, Richerson GB, Blumenfeld H (2016) Impaired serotonergic brainstem function during and after seizures. J Neurosci 36:27112722. 